\title{
Rapid Detection of Salmonella enterica in Food Using a Compact Disc-Shaped Device
}

\author{
Shunsuke Furutani ${ }^{1}$, Mitsutoshi Kajiya ${ }^{2}$, Narumi Aramaki ${ }^{2}$ and Izumi Kubo ${ }^{2, *}$ \\ Received: 13 November 2015; Accepted: 12 January 2016; Published: 15 January 2016 \\ Academic Editor: Marc Madou \\ 1 Health Research Institute, National Institute of Advanced Industrial Science and Technology (AIST), \\ 1-8-31 Midorigaoka, Ikeda, Osaka 563-8577, Japan; shunsuke-furutani@aist.go.jp \\ 2 Graduate School of Engineering, Soka University, 1-236 Tangi, Hachioji, Tokyo 192-8577, Japan; \\ e1056103@soka.ac.jp (M.K.); e15m5601@soka-u.jp (N.A.) \\ * Correspondence: kubo@soka.ac.jp; Tel.: +81-42-691-9450; Fax: +81-42-691-9312
}

\begin{abstract}
Rapid detection of food-borne pathogens is essential to public health and the food industry. Although the conventional culture method is highly sensitive, it takes at least a few days to detect food-borne pathogens. Even though polymerase chain reaction (PCR) can detect food-borne pathogens in a few hours, it is more expensive and unsatisfactorily sensitive relative to the culture method. We have developed a method to rapidly detect Salmonella enterica by using a compact disc (CD)-shaped device that can reduce reagent consumption in conventional PCR. The detection method, which combines culture and PCR, is more rapid than the conventional culture method and is more sensitive and cheaper than PCR. In this study, we also examined a sample preparation method that involved collecting bacterial cells from food. The bacteria collected from chicken meat spiked with S. enterica were mixed with PCR reagents, and PCR was performed on the device. At a low concentration of S. enterica, the collected S. enterica was cultured before PCR for sensitive detection. After cultivation for $4 \mathrm{~h}$, S. enterica at $1.7 \times 10^{4}$ colony-forming units (CFUs) $\mathrm{g}^{-1}$ was detected within $8 \mathrm{~h}$, which included the time needed for sample preparation and detection. Furthermore, the detection of 30 CFUs. $\mathrm{g}^{-1}$ of $S$. enterica was possible within $12 \mathrm{~h}$ including $8 \mathrm{~h}$ for cultivation.
\end{abstract}

Keywords: PCR; rapid detection; Salmonella enterica; compact disc; food; meat

\section{Introduction}

Rapid detection of food-borne pathogens is of great importance to public health and the food industry. Food-borne illnesses are often caused by bacteria, viruses, chemical agents or natural toxins. Half of all food-borne illnesses are caused by bacteria such as Salmonella spp., Escherichia coli or Staphylococcus. Especially, Salmonella enterica is the causative agent of human salmonellosis and one of the most notorious food-borne pathogens worldwide [1]. Infection by S. enterica is often caused by ingesting chicken meat or eggs. This is because chickens sometimes carry S. enterica in their intestines. Even if chickens or eggs are not infected by S. enterica when they are produced, after production of these materials, there are various opportunities for infection by S. enterica, before they are consumed, including during processing, transportation, packaging, sales, cooking and serving food. Therefore, rapid detection of $S$. enterica at all stages from production to eating is necessary to avoid an outbreak. There is a need for faster and simpler screening tests to detect $S$. enterica in not only foods but also food manufacturing plants.

The conventional method to detect $S$. enterica requires multiple subculture steps followed by biochemical tests. Although the conventional culture method is highly sensitive and can detect a few colony-forming units (CFUs) $\mathrm{mL}^{-1}$ of $S$. enterica, it takes at least three days to confirm that 
food is not contaminated by any Salmonella species, and five to six days to clarify whether food is contaminated by S. enterica [2]. Separately, many researchers have reported the rapid detection of food-borne pathogens using the polymerase chain reaction (PCR) [3-8]. A number of PCR assays specific to different Salmonella genes such as the 16S rRNA gene [4], the invA gene [5], the phoP gene [6], the $p h o E$ gene [7] and the fim $A$ gene [8] have been reported. The highly specific identification of pathogens is enabled by PCR in a few hours. However, Fachmann et al. reported that the limit of detection (LOD) of real-time PCR-based detection of S. enterica was $10^{3} \mathrm{CFUs} \cdot \mathrm{mL}^{-1}$ [9], which is a higher concentration than that of the conventional culture method. In addition, it is necessary to reduce the amount of PCR reagents used to assay many samples because PCR reagents are expensive.

The microfluidic devices are useful to reduce the reagents because the handling of a small amount of reagent is enabled in the devices. Especially, the development of the centrifugally driven microfluidic platforms, which are generally referred to as "Lab-on-a-Disk", is of great interest [10]. The advantage of Lab-on-a-disk is to eliminate bulky external pumps for liquid transfer. Sundberg et al. reported digital PCR on Lab-on-a-Disk in 2010 [11]. The PCR mixture that contained plasmid DNA was divided into one thousand $33 \mathrm{~nL}$ microchambers by spinning the disk. Then, the PCR mixture in the microchambers were separated by forcing mineral oil through the spiral channel and performed PCR in each microchambers. Schuler et al. also reported digital droplet PCR on Lab-on-a-disk in 2015 [12]. The PCR mixture contained DNA was divided into eleven thousands $1.8 \mathrm{~nL}$ droplets and PCR on the disk was performed. In these reports, they performed the PCR from not cells but only DNA.

We have developed a compact disc (CD)-shaped device for single cell isolation to detect isolated cells easily and rapidly without the need for a micro-pumping system [13]. By spinning the device, bacterial cells can be isolated in microchambers on the device, regardless of cell size. More specifically, when the concentration of bacterial cells is 200 cells. $\mu \mathrm{L}^{-1}$ or lower, almost all bacterial cells were isolated as a single cell into each microchambers on the device. Moreover, we successfully achieved sequential PCR of the invA gene of isolated S. enterica by hot cell-direct PCR without the need to extract DNA [14]. In this device, only $1 \mu \mathrm{L}$ of PCR reagent is needed for one sample, so the amount of reagents consumed in our device is 25 times lower than that for conventional PCR, i.e., $25 \mu \mathrm{L}$. Furthermore, in the conventional PCR method, $1 \mu \mathrm{L}$ of PCR reagent in a tube is too little to perform PCR normally, because the reagent is evaporated. In our device, the LOD of $S$. enterica is $5 \times 10^{4}$ cells. $\mathrm{mL}^{-1}$ [14]. Therefore, improvement of LOD is essential to detect S. enterica in food. Furthermore, since food may be contaminated by various bacteria, one objective of this study was to be able to detect S. enterica from other bacterial cells using the device. Therefore, at first, we examined the specific detection of S. enterica from a mixture of S. enterica and E. coli, which is the most common bacterium. The food sample selected for this study was ground chicken because $S$. enterica infection is often caused by consuming chicken. Moreover, we evaluated the speed of detection of S. enterica in food using a combination of culture and PCR to improve the LOD of S. enterica in the device. By combining the culture method and PCR on the CD-shaped device, our detection method was more rapid than the conventional culture method, and more sensitive than real-time PCR based method.

\section{Experimental Section}

\subsection{Bacterial Cells}

S. enterica and E. coli were purchased from RIKEN BRC (Tsukuba, Japan). Nutrient broth was purchased from Sanko Junyaku Co., Ltd. (Tokyo, Japan). Nutrient broth with $0.5 \% \mathrm{NaCl}$ medium (NB medium) ( $\mathrm{pH}$ 7.2) and buffered peptone water (BPW) ( $\mathrm{pH}$ 7.2) was used to grow S. enterica while Lysogeny Broth (LB) medium ( $\mathrm{pH}$ 7.0) was used as the growth medium for E. coli. Bacterial cells were cultivated in liquid media overnight at $37^{\circ} \mathrm{C}$. Cell concentration was confirmed under an optical microscope and diluted to the desired concentration with $10 \mathrm{mM}$ phosphate buffer solution (PBS). Furthermore, the number of CFUs was confirmed by cultivation on agar medium at $37^{\circ} \mathrm{C}$ for $24 \mathrm{~h}$. 


\subsection{PCR Reagents and Real-Time PCR}

PCR was performed using a CycleavePCR Salmonella Detection Kit Ver. 2.0 (TaKaRa, Tokyo, Japan). This kit contains a $2 \times$ Cycleave reaction mixture and a $5 \times \mathrm{SIN}$ primer/probe mix. The Cycleave reaction mixture contains Taq polymerase, RNaseH, buffer, dNTP mixture and internal control DNA. The internal control DNA is a sequence non-related to the target gene and works to detect false negatives. When the target gene is not detected, and the internal control DNA shows a positive signal, this indicates the absence of PCR inhibition and that the concentration of the target gene in the sample is below the detection limit. When both target and internal control are not detected, this indicates that PCR does not occur properly and that a reaction inhibitory factor exists in the sample. The SIN primer/probe mix is a mixture of primer and probe to detect the inv $A$ gene and internal control DNA. The probe for the invA gene was labeled with 6-carboxyfluorescein (FAM) and a quencher. The probe for the internal control DNA was labeled with X-Rhodamine (ROX) and a quencher. The increase in fluorescence from FAM and ROX occurred after an amplification of the invA gene and internal control DNA, respectively. After the probe is hybridized to the PCR product, it is cut by $\mathrm{RNaseH}$. Then fluorescence intensity is increased by uncoupling the quencher from the probe. The reaction mixture consisted of a $1 \times$ Cycleave reaction mixture, a $1 \times$ SIN primer/probe mix, $0.5 \mathrm{U} \cdot \mu \mathrm{L}^{-1}$ Taq polymerase (TaKaRa EX Taq hot start version) and the desired concentration of the suspension of S. enterica. The reaction mixture without S. enterica was used as the negative control.

The number of washing treatments necessary to remove the inhibitor from ground chicken in PCR was also evaluated. In this experiment, $5 \mu \mathrm{L}$ of $S$. enterica recovered by Percoll ${ }^{\circledR}$ (GE Healthcare, Tokyo, Japan) was used as a template in real-time PCR, which was performed with a 7500 Real-Time PCR System (Applied Biosystems, Tokyo, Japan). Thermal cycling was initiated at $95^{\circ} \mathrm{C}$ for 2 min to lyse $S$. enterica, followed by 40 cycles of $95^{\circ} \mathrm{C}$ for $5 \mathrm{~s}, 55^{\circ} \mathrm{C}$ for $10 \mathrm{~s}$, and $72{ }^{\circ} \mathrm{C}$ for $30 \mathrm{~s}$.

\subsection{Fabrication of CD-Shaped Device}

The CD-shaped device was fabricated according to a previously described method [14]. In brief, the microchannel and microchambers $(40 \mu \mathrm{m}$ in depth) were fabricated by deep reactive ion etching (deep-RIE) on a silicon wafer $(\phi=10 \mathrm{~cm} ; 525 \mu \mathrm{m}$ thick). The etched silicon wafer was anodically bonded to a glass plate $(500 \mu \mathrm{m}$ thick) that has holes $(\phi=2 \mathrm{~mm})$ for inlets and vents bored by microblasting. As shown in Figure 1a, on a CD-shaped device, 24 zig-zag shaped microchannels are arranged, and 313 microchambers are arrayed on the outer side of each microchannel. The dimensions of the microchambers are $300 \mu \mathrm{m}$ (width) $\times 200 \mu \mathrm{m}$ (height) $\times 40 \mu \mathrm{m}$ (depth), and the microchamber can accommodate approximately $1 \mathrm{~nL}$ of sample solution. The gap between microchambers is approximately $200 \mu \mathrm{m}$. To prevent the displacement of solution to neighboring microchambers, the surface of the microchannels and microchambers was modified by triethoxymethylsilane (Wako, Osaka, Japan). For this modification, we infused $3 \mu \mathrm{L}$ of triethoxymethylsilane into each microchannel by capillary force then baked the device overnight at $80^{\circ} \mathrm{C}$. After baking, using a microscope, we confirmed that the triethoxymethylsilane did not remain in the microchannel and microchambers. 


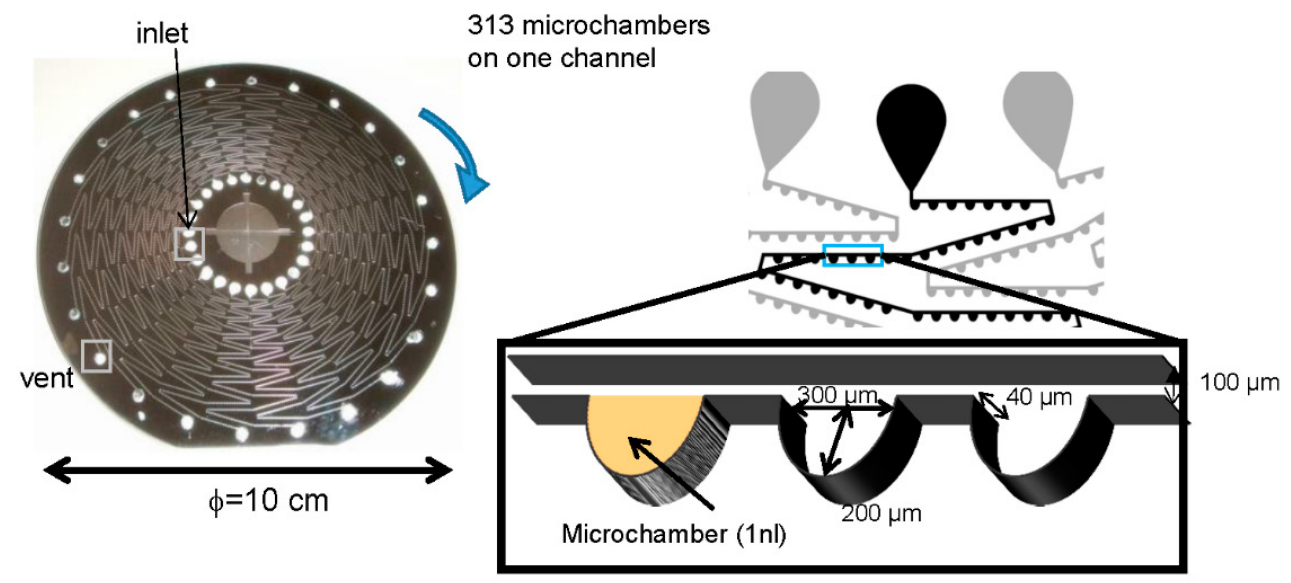

(a)

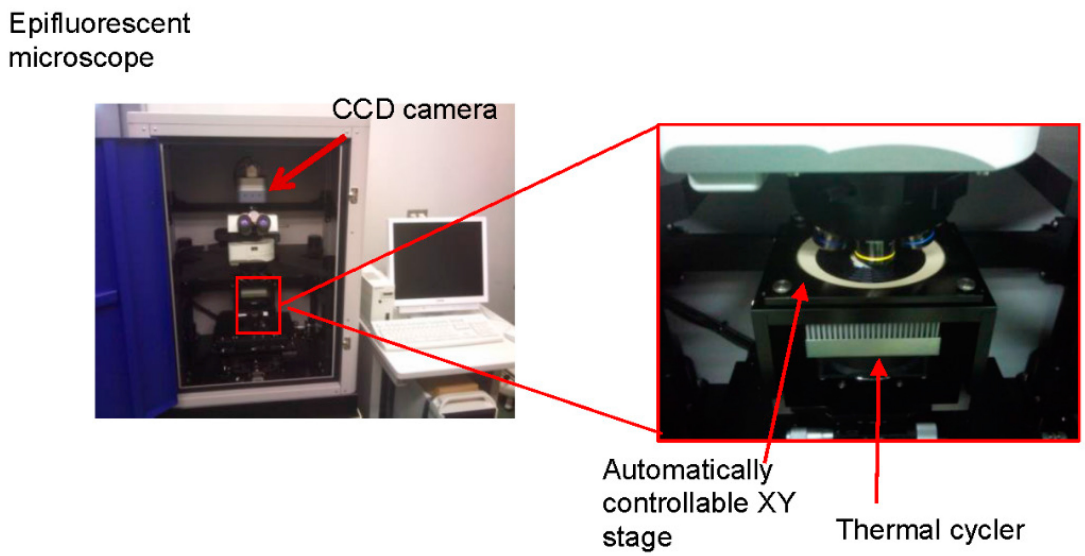

(b)

Figure 1. (a) design of the CD-shaped device; (b) the detection system was fabricated to acquire images of all microchambers automatically.

\subsection{Detection of S. Enterica Using a CD Shaped Device}

We previously developed a detection system that could detect the fluorescence image of all microchambers in a microchannel of the CD-shaped device before and after PCR [15]. As shown in Figure $1 b$, the detection system is composed of an epifluorescence microscope and a charge coupled device (CCD) camera to detect microchambers, a thermal cycler for PCR, and a controllable XY stage for automatic detection of all microchambers in a microchannel. In this study, detection of S. enterica using the CD-shaped device was performed by the detection system as shown in Figure 2a. Briefly, $1 \mu \mathrm{L}$ of reaction mixture was introduced into an inlet of the device. By spinning the device, the reaction mixture was completely isolated in the microchambers. Before PCR, the fluorescence intensity of each microchamber was measured by the detection system. Then, the CD-shaped device was placed on the stage of a thermal cycler (Astec, Tokyo, Japan). This stage was shaped to fit the CD-shaped device. Thermal cycling was initiated at $95^{\circ} \mathrm{C}$ for $2 \mathrm{~min}$ as heat treatment to lyse S. enterica, followed by 40 cycles of $95^{\circ} \mathrm{C}$ for $5 \mathrm{~s}, 55^{\circ} \mathrm{C}$ for $10 \mathrm{~s}$, and $72^{\circ} \mathrm{C}$ for $10 \mathrm{~s}$. After PCR, the fluorescence intensity of each microchamber was measured by the detection system. The relative fluorescence intensity (RFI) is expressed as:

$$
\mathrm{RFI}=\frac{\text { Fluorescence intensity after PCR }}{\text { Fluorescence intensity before PCR }}
$$

As shown in Figure 2b, in the sample case with a low concentration of S. enterica in ground chicken, $500 \mu \mathrm{L}$ of sediment after Percoll ${ }^{\circledR}$ (GE Healthcare Japan, Tokyo, Japantreatment was mixed 
with $5 \mathrm{~mL}$ of Nutrient broth with $0.5 \% \mathrm{NaCl}(\mathrm{NB})$ liquid medium and cultured at $37^{\circ} \mathrm{C}$ for 4 or $8 \mathrm{~h}$. After cultivation and washing with PBS, this S. enterica sample was detected on the CD-shaped device.

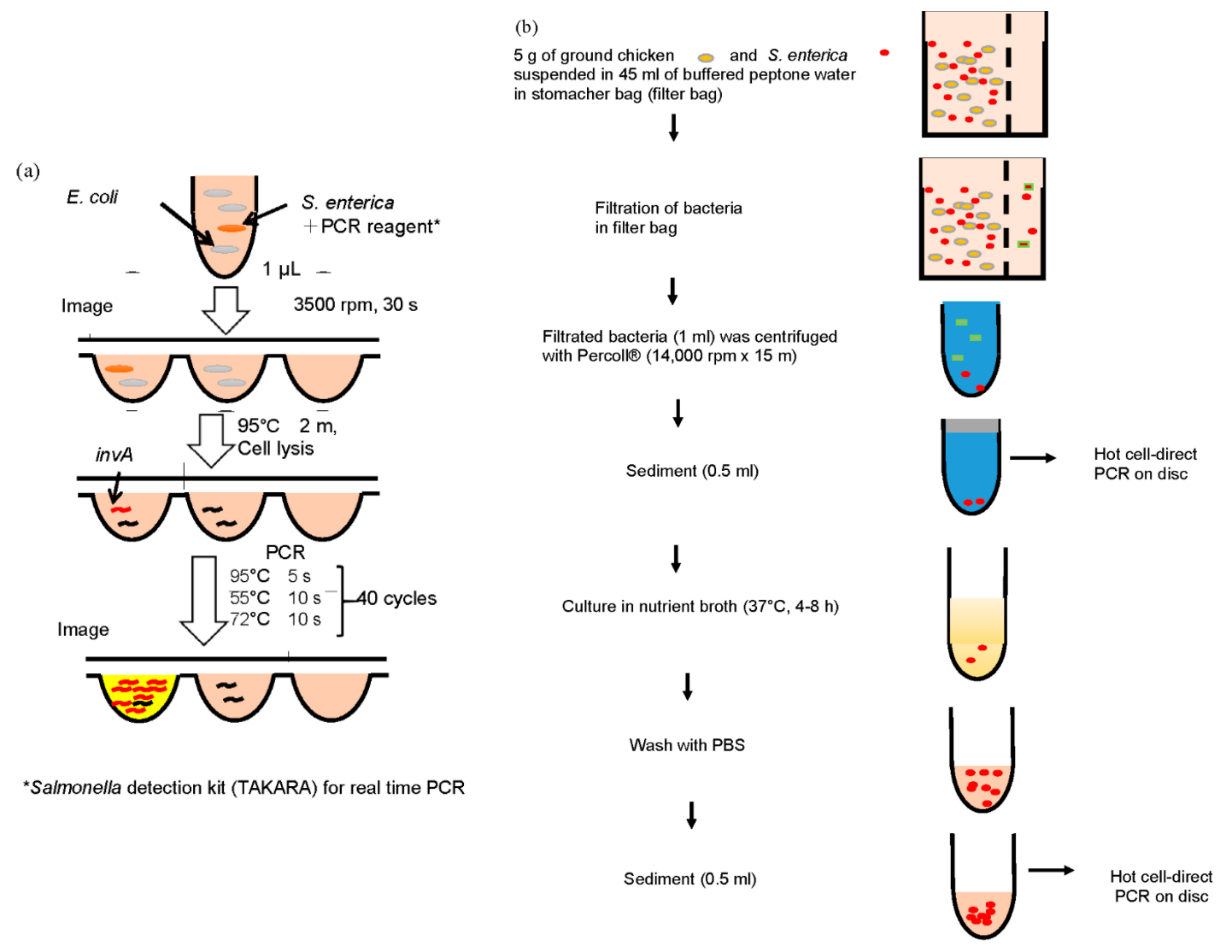

Figure 2. Detection scheme. (a) detection of S. enterica using the CD-shaped device by the detection system; (b) pre-treatment of chicken meat spiked with S. enterica.

\subsection{Separation of S. Enterica from Chicken}

Bacterial samples from chicken meat as the food sample were prepared as follows. Ground chicken was obtained from a local grocery and used as the food sample. To recover bacteria from chicken meat, $5 \mathrm{~g}$ of ground chicken and $45 \mathrm{~mL}$ of BPW were mixed in a stomacher bag (Atect, Osaka, Japan). After stirring for $1 \mathrm{~min}, 100 \mu \mathrm{L}$ of filtrate, which was passed through the filter of the stomacher bag, was cultivated on NB agar medium and LB medium at $37^{\circ} \mathrm{C}$ to detect the existence of S. enterica and E. coli.

Samples were prepared for PCR as follows (Figure 2b). The desired concentration of S. enterica cells was spiked to $5 \mathrm{~g}$ of ground chicken and mixed with $45 \mathrm{~mL}$ of BPW in the stomacher bag. After stirring for $1 \mathrm{~min}, 1 \mathrm{~mL}$ of filtrate was mixed with $0.7 \mathrm{~mL}$ of Percoll ${ }^{\circledR}$. After the mixture was centrifuged at $14000 \mathrm{rpm}$ for $15 \mathrm{~min}$ at $4{ }^{\circ} \mathrm{C}, 0.5 \mathrm{~mL}$ of sediment was collected as the $S$. enterica sample. After washing the sample with $10 \mathrm{mM}$ PBS one to three times, part of it served for hot cell-direct PCR while another part was cultivated on $\mathrm{NB}$ agar medium at $37^{\circ} \mathrm{C}$.

\section{Results and Discussion}

\subsection{Detection of S. Enterica in Reaction Mixture with E. coli on CD-Shaped Device}

The detection of $S$. enterica contamination in food would require discrimination from among various bacteria. Therefore, we examined whether $S$. enterica was selectively detected by our detection system from a sample containing many general bacteria. In this study, $10^{3} \mathrm{CFUs} \cdot \mu \mathrm{L}^{-1}$ of E. coli 
was used as the general bacteria, because the standard value of the number of the general bacteria for non-heated food was less than $10^{6} \mathrm{CFUs} \cdot \mathrm{g}^{-1}$. In this experiment, 50, 100 and 400 cells $\mu \mathrm{L}^{-1}$ of S. enterica with 1000 cells. $\mu \mathrm{L}^{-1}$ of E. coli were examined. Figure 3a displays fluorescence images of the microchambers before and after PCR. RFI indicates the ratio of fluorescence intensity after PCR to that before PCR in this study. In this case, although the fluorescence intensity of the microchambers in the center and on the right did not increase, those on the left side increased clearly after PCR. Figure 3b shows the RFIs of 200 microchambers from upstream to downstream for 50 cells $\mu \mathrm{L}^{-1}$ of $S$. enterica with 1000 cells. $\mu \mathrm{L}^{-1}$ of E. coli. To determine the detection threshold value of S. enterica, RFI of the negative control was measured on the CD-shaped device and was lower than 1.4. Therefore, microchambers displaying an RFI value greater than 1.4 were identified as those containing $S$. enterica in this study. The chamber with RFI value greater than 1.4 was observed around the turn of microchannel. We observe such localization on the isolation of rod-like bacteria such as salmonella sp. but no localization of ball-shaped cell and particle was observed [15]. Such localization might be caused by the shape of the isolated bacteria. As shown in Table 1, the number of microchambers with an RFI value greater than 1.4 was 19,36, and 92 in 50, 100 and 400 cells. $\mu \mathrm{L}^{-1}$ of S. enterica, respectively. Furthermore, these numbers depended on the concentration of $S$. enterica. Therefore, we could selectively detect $S$. enterica in a sample containing large number of E. coli cells. In our previous report [14], the number of microchambers with high fluorescence intensity in 400 cells. $\mu \mathrm{L}^{-1}$ of S. enterica in our CD-shaped device was 90 microchambers among 200 microchambers. The observed number of microchambers with RFI value greater than 1.4 was larger than expected number. In this experiment, cell concentration was confirmed under an optical microscope but not by colony formation, so that we might detect dead S. enterica cells as well as living cells.

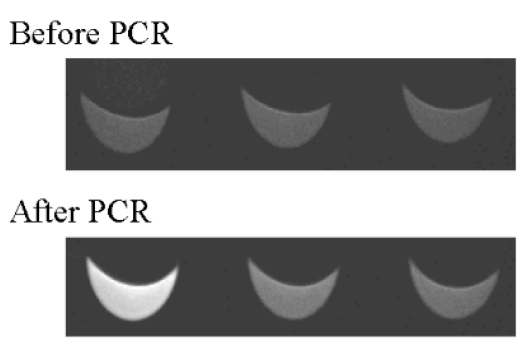

(a)

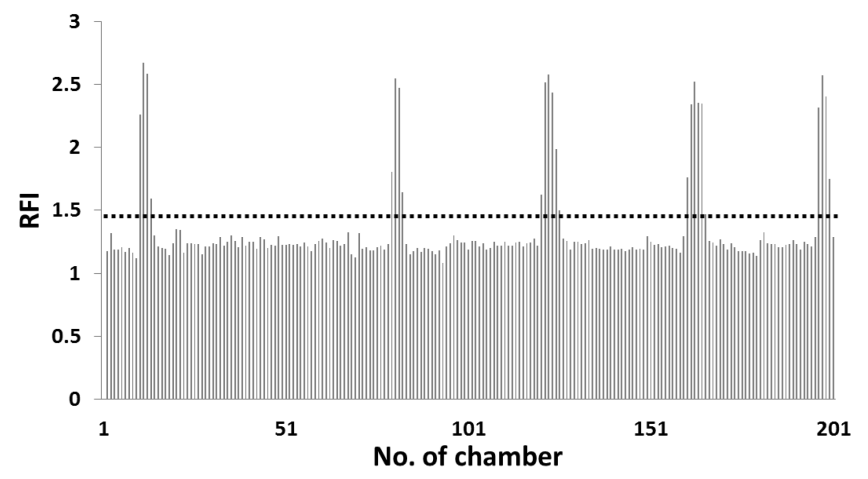

(b)

Figure 3. (a) fluorescence image of microchambers on the CD-shaped device before and after PCR; (b) RFIs of 200 microchambers from upstream to downstream for 50 cells. $\mu \mathrm{L}^{-1}$ of $S$. enterica with 1000 cells. $\mu \mathrm{L}^{-1}$ of E. coli.

Table 1. Number of microchambers with relative fluorescence intensity (RFI) $>1.4$.

\begin{tabular}{cc}
\hline Concentration of $\boldsymbol{S}$. enterica $\left(\right.$ cells $\boldsymbol{\mu} \mathbf{L}^{-1}$ ) & Number of Microchambers with RFI > 1.4 \\
\hline 50 & 19 \\
100 & 36 \\
400 & 92 \\
\hline
\end{tabular}

\subsection{Separation of S. enterica from Chicken}

Generally speaking, ground chicken, which is purchased from a grocery store, has a small amount of bacteria. Therefore, before examining the recovery rate for $S$. enterica-spiked chicken, the number of bacteria contaminated in chicken purchased from a grocery store was confirmed by the colony counting method. The concentration of general bacteria contaminated in chicken was $200 \mathrm{CFUs} \cdot \mathrm{g}^{-1}$, 
but no $S$. enterica cells were found. Generally, the infection by S. enterica is often caused by ingesting food contaminated by more than $10^{5}$ to $10^{6}$ CFUs [16]. Then, the recovery rate for S. enterica-spiked chicken was examined. At first, $2.3 \times 10^{7} \mathrm{CFUs}$ of $S$. enterica was added to $5 \mathrm{~g}$ of ground chicken and $45 \mathrm{~mL}$ of BPW in a stomacher bag. After treatment with Percoll ${ }^{\circledR}$, the number of S. enterica cells, which were collected from $S$. enterica-spiked chicken, was confirmed by colony counting. The concentration of $S$. enterica was $2.7 \times 10^{6}$ CFUs. $g^{-1}$. Therefore, the recovery rate for S. enterica was $59 \%$ after Percoll ${ }^{\circledR}$ treatment. The remaining $41 \%$ of $S$. enterica would likely be adsorbed to the surface of the ground chicken or the stomacher bag.

To sufficiently remove the inhibitor to PCR in the food sample, the number of washes after Percoll ${ }^{\circledR}$ treatment was examined. In this experiment, $1.5 \times 10^{9} \mathrm{CFUs} \cdot \mathrm{g}^{-1}$ of S. enterica was spiked to ground chicken. As a control sample, the same concentration of S. enterica in PBS was examined. As shown in Figure 4, when S. enterica was not spiked to chicken (control), the RFI of FAM for the inv $A$ gene and the RFI of ROX for the internal control DNA were 2.7 and 10, respectively. After Percoll ${ }^{\circledR}$ treatment $^{2}$ and washing one to three times, the RFI of FAM was 2.6, 2.7 and 2.8, respectively while the RFI of ROX was 6.3, 9.8 and 11, respectively. The low RFI of ROX observed after washing once indicated that the inhibitor in the food sample was not sufficiently removed. In contrast, the inhibitor in food samples was sufficiently removed when samples were washed at least twice. Therefore, the number of washes was set to two to sufficiently remove the inhibitor.

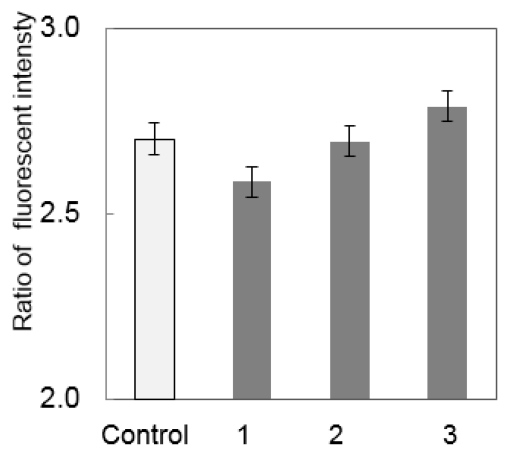

(a)

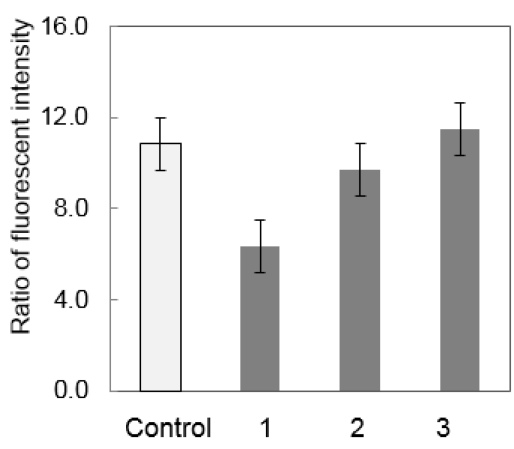

(b)

Figure 4. Evaluation of the efficiency of PCR for the number of washes. (a) RFI of FAM for the inv $A$ gene; (b) RFI of ROX for the internal control DNA. Error bars indicate standard deviation (SD) $(n=3)$.

\subsection{Detection of S. enterica from Chicken on CD-Shaped Device}

After the number of washes was optimized, the S. enterica sample spiked to ground chicken was examined on the CD-shaped device. As the threshold value of RFI for the detection of S. enterica was 1.4 on the device, a microchamber with an RFI value greater than 1.4 was identified as one containing S. enterica. Spiked concentrations of $4.6 \times 10^{7}, 4.6 \times 10^{6}, 4.6 \times 10^{5}$ and $4.6 \times 10^{4} \mathrm{CFUs}^{\mathrm{g}} \mathrm{g}^{-1}$ were examined immediately after washing. As shown in Table 2 , in the case of $4.6 \times 10^{7}, 4.6 \times 10^{6}$, $4.6 \times 10^{5}$ and $4.6 \times 10^{4} \mathrm{CFUs} \cdot \mathrm{g}^{-1}, 170,24,6$ and 0 microchambers, respectively exceeded the threshold. Furthermore, for every concentration, microchambers with an RFI value lower than the threshold were observed: the average RFI of those microchambers was approximately 1.2, almost equal to that of the negative control. In the case of $4.6 \times 10^{5} \mathrm{CFUs} \cdot \mathrm{g}^{-1}$, the concentration of $S$. enterica in the reaction mixture was expected to be 9 CFUs $\mu \mathrm{L}^{-1}$. Taking the recovery into consideration, the number of microchambers that exceeded the threshold was expected to be three or four, while the observed number was six in this experiment. This result might suggest that dead S. enterica were detected by PCR. Furthermore, cultivation before PCR is necessary to detect $S$. enterica at concentrations lower than $4.6 \times 10^{4}$ CFUs. $g^{-1}$. 
Table 2. Number of microchambers exceeded the threshold.

\begin{tabular}{|c|c|}
\hline Concentration of S. enterica (CFUs. $\mathrm{g}^{-1}$ ) & Number of Microchambers Exceeded the Threshold \\
\hline $4.6 \times 10^{4}$ & 0 \\
\hline $4.6 \times 10^{5}$ & 6 \\
\hline $4.6 \times 10^{6}$ & 24 \\
\hline $4.6 \times 10^{7}$ & 170 \\
\hline
\end{tabular}

To achieve highly sensitive detection, S. enterica collected from ground chicken following filtration and Percoll ${ }^{\circledR}$ treatment was cultivated before PCR and detection on the CD-shaped device. Figure 5a indicates the number of microchambers that exceeded the threshold after PCR following cultivation for $4 \mathrm{~h}$. The number of microchambers with $1.7 \times 10^{6}, 1.7 \times 10^{5}$ and $1.7 \times 10^{4} \mathrm{CFUs} \cdot \mathrm{g}^{-1}$ was 184, 124 and 10, respectively. In contrast, without cultivation, six microchambers exceeded the threshold when $S$. enterica concentration was $1.7 \times 10^{6} \mathrm{CFUs} \cdot \mathrm{g}^{-1}$. Furthermore, when S. enterica concentration was $1.7 \times 10^{5}$ and $1.7 \times 10^{4} \mathrm{CFUs} \cdot \mathrm{g}^{-1}$, no microchambers exceeded the threshold. Therefore, the detection of S. enterica by PCR when S. enterica concentration was $1.7 \times 10^{4} \mathrm{CFUs} \cdot \mathrm{g}^{-1}$ was confirmed within $8 \mathrm{~h}$ between sampling and detection. The number of microchambers that exceeded the threshold after cultivation for $8 \mathrm{~h}$ is shown in Figure $5 \mathrm{~b}$. In the case of 240, 120, 60 and 30 CFUs. $\mathrm{g}^{-1}$, the number of microchambers that exceeded the threshold was 105, 37, 30 and 20, respectively. The sensitive detection of $30 \mathrm{CFUs} \cdot \mathrm{g}^{-1}$ of $S$. enterica was possible on the CD-shaped device in $12 \mathrm{~h}$, which included $8 \mathrm{~h}$ of cultivation. These results demonstrated that this method is more than 300 times more sensitive than the real-time PCR method and more than 10 times as rapid as the conventional culture method. Furthermore, detection of the number of only viable bacterial cells is also important in food-borne illness. By cultivating S. enterica before PCR in the CD-shaped device, we could detect only viable $S$. enterica in a sample carrying a low concentration of this bacterium because not only viable $S$. enterica but also dead bacterial cells were not detected at less than $4.6 \times 10^{4} \mathrm{CFUs} \cdot \mathrm{g}^{-1}$ of $S$. enterica without cultivation.

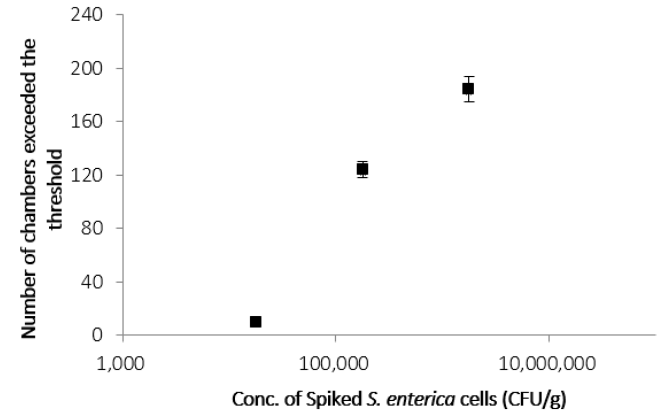

(a)

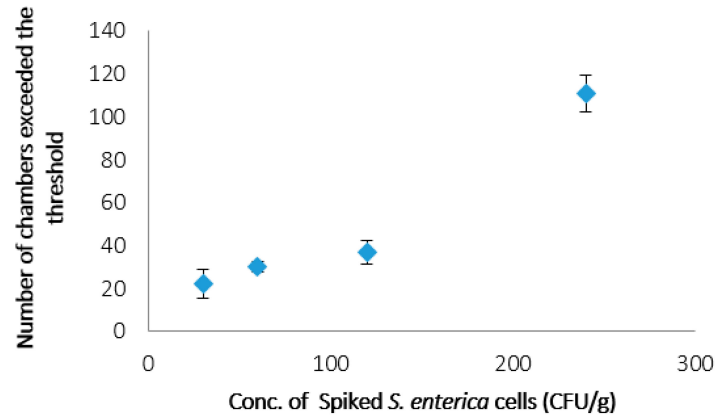

(b)

Figure 5. (a) number of microchambers exceeded the threshold after cultivation for $4 \mathrm{~h}$; (b) number of microchambers exceeded the threshold after cultivation for $8 \mathrm{~h}$. Error bars indicate standard deviation (SD) $(n=3)$.

\section{Conclusions}

The recovery rate for S. enterica after sample preparation was $59 \%$. The inhibitor in the food sample was sufficiently removed after two washes with $10 \mathrm{mM}$ PBS. The detection of S. enterica at $4.6 \times 10^{6} \mathrm{CFUs} \cdot \mathrm{g}^{-1}$ was confirmed after $4 \mathrm{~h}$ without cultivation before PCR. After cultivation for $4 \mathrm{~h}$, S. enterica at $1.7 \times 10^{4} \mathrm{CFUs} \cdot \mathrm{g}^{-1}$ was detected after $8 \mathrm{~h}$. Furthermore, the sensitive detection of $30 \mathrm{CFUs} \cdot \mathrm{g}^{-1}$ of $S$. enterica was possible on the CD-shaped device within $12 \mathrm{~h}$, which included $8 \mathrm{~h}$ for cultivation. Our detection method is more than 10 times as rapid as the conventional culture method 
and more than 300 times more sensitive than the real-time PCR method. Cultivating S. enterica before PCR allows for the rapid and sensitive detection of viable S. enterica in a sample of S. enterica in food.

Acknowledgments: This work was supported by funding from the Ministry of Education, Culture, Sports, Science and Technology (MEXT), Japan, and the Matching Fund for Private Universities, S1001013, 2010-2015.

Author Contributions: Shunsuke Furutani and Izumi Kubo designed the experiments, analyzed data and wrote the paper. Mitsutoshi Kajiya and Narumi Aramaki performed the experiments and analyzed data and images.

Conflicts of Interest: The authors declare no conflict of interest.

\section{References}

1. Hoelzer, K.; Switt, A.I.M.; Wiedmann, M. Animal contact as a source of human non-typhoidal salmonellosis. Vet. Res. 2011, 42, 34. [CrossRef] [PubMed]

2. Japan Environmental Health Bureau, Ministry of Health and Welfare, Ed.; Standard Methods of Analysis in Food Safety Regulation-Biology; Japan Food Hygiene Association: Tokyo, Japan, 1990.

3. Salazar, J.K.; Wang, Y.; Yu, S.; Wang, H.; Zhang, W. Polymerase chain reaction-based serotyping of pathogenic bacteria in food. J. Microbiol. Methods 2015, 110, 18-26. [CrossRef] [PubMed]

4. Iida, K.; Abe, A.; Matsui, H.; Wakayama, S.; Kawahara, K. Rapid and sensitive method for detection of Salmonella strains using a combination of polymerase chain reaction and reverse dot-blot hybridization. FEMS Microbiol. Lett. 1993, 114, 167-172. [CrossRef] [PubMed]

5. Pahn, K.; de Grandis, S.A.; Clarke, R.C.; McEwen, S.A.; Galan, J.E.; Ginocchio, C.; Curtiss, R.; Gyles, C.L. Amplification of an invA gene sequence of Salmonella typhimurium by polymerase chain reaction as specific method of detection of Salmonella. Mol. Cell. Probes 1992, 6, 271-279.

6. Way, J.S.; Josephson, K.L.; Pillai, S.D.; Abbaszadegan, M.; Gerba, C.P.; Pepper, I.L. Specific detection of Salmonella spp. by multiplex polymerase chain reaction. Appl. Environ. Microbiol. 1993, 59, 1473-1479. [PubMed]

7. Kobayashi, K.; Taguchi, M.; Seto, K. Polymerase chain reaction (PCR) method for the detection of Salmonella by using Chelex resin after enrichment culture. J. Jpn. Assoc. Infect. Dis. 1994, 68, 1203-1210. [CrossRef]

8. Cohen, H.J.; Mechanda, S.M.; Lin, W. PCR amplification of the fimA gene sequence of Salmonella typhimurium, a specific method for detection of Salmonella spp. Appl. Environ. Microbiol. 1996, 62, 4303-4308. [PubMed]

9. Fachmann, M.S.R.; Josefsen, M.H.; Hoorfar, J.; Nielsen, M.T.; Lofstrom, C. Cost-effective optimization of real-time PCR based detection of Campylobacter and Salmonella with inhibitor tolerant DNA polymerases. J. Appl. Microbiol. 2015, 119, 1391-1402. [CrossRef] [PubMed]

10. Strohmeier, O.; Keller, M.; Schwemmer, F.; Zehnle, S.; Mark, D.; von Stettn, F.; Zengerle, R.; Paust, N. Centrifugal microfluidic platforms: Advanced unit operations and applications. Chem. Soc. Rev. 2015, 44, 6187-6229. [CrossRef] [PubMed]

11. Sundberg, S.O.; Wittwer, C.T.; Gao, C.; Gale, B.K. Spinning Disk Platform for Microfluidic Digital Polymerase Chain Reaction. Anal. Chem. 2010, 82, 1546-1550. [CrossRef] [PubMed]

12. Schuler, F.; Trotter, M.; Geltman, M.; Schwemmer, F.; Wadle, S.; Domínguez-Garrido, E.; López, M.; Cervera-Acedo, C.; Santibáñez, P.; von Stetten, F.; et al. Digital droplet PCR on disk. Lab Chip 2016, 16, 208-216. [CrossRef] [PubMed]

13. Furutani, S.; Nagai, H.; Kubo, I. Single cell isolation on a centrifugal flow disk with integrated tandem microchambers. Sens. Lett. 2008, 6, 961-965. [CrossRef]

14. Furutani, S.; Nagai, H.; Takamura, Y.; Kubo, I. Compact disk (CD)-shaped device for single cell isolation and PCR of the specific gene in the isolated cell. Anal. Bioanal. Chem. 2010, 398, 2997-3004. [CrossRef] [PubMed]

15. Furutani, S.; Shozen, N.; Nagai, H.; Aoyama, Y.; Kubo, I. Development of a detection system for expressed genes in isolated single Jurkat cells. Sens. Mater. 2014, 26, 623-635.

16. JFRL News. Salmonella Food Poisoning, the Importance and Difficulty of the Countermeasures. Available online: http://www.jfrl.or.jp/jfrlnews/files/news_no02.pdf (accessed on 24 December 2015). (In Japanese). 